untreated patients with cystic fibrosis at any age. It is more stable than trypsin in the faeces and less likely to result in false low values. Faecal collections for fat estimation are difficult but are essential if malabsorption of fat is to be proved. The diagnosis should be questioned if the faecal fat output is normal. Estimation of the concentrations of fat soluble vitamins is another useful indirect method of indicating the presence of a gastrointestinal lesion. In a previous study 28 of 30 children with cystic fibrosis who were not receiving vitamin $E$ supplements had plasma concentrations more than two standard deviations below the control mean. ${ }^{4}$ In virtually all children with cystic fibrosis over the age of five years the pancreas looks abnormal on ultrasonography.

Although 5-10\% of patients with cystic fibrosis do not have clinical pancreatic dysfunction, $5-10 \%$ have mild and $85 \%$ have severe pancreatic disease. ${ }^{5}$ The fact that the pancreatic function tests, although indirect, were normal in our patients is strong evidence against a gastrointestinal lesion and therefore the diagnosis of cystic fibrosis.

The most common diagnostic error is the uncritical acceptance of an abnormal sweat test. It is important that this test is performed by a laboratory used to carrying out the investigation and that the results are interpreted correctly in the light of the patient's age, clinical findings, and additional investigations. It is also important to analyse the chloride as well as the sodium content of the sweat, as in patients with cystic fibrosis whose sweat electrolytes are equivocal $(50-70 \mathrm{mmol} / \mathrm{l})$ the chloride concentration is usually higher than the sodium concentration, whereas in normal subjects the reverse is the case. $^{6}$

The implications of an incorrect diagnosis of cystic fibrosis can be extensive, the children receiving unnecessary treatment and investigations. In addition to the anxiety generated by such a diagnosis and worries regarding the child's future, there are genetic implications that may influence decisions about further pregnancies.

It is important, therefore, to reconsider the diagnosis where typical clinical features are either not present or only mild, and to have two reliable sweat tests as well as evidence of malabsorption or pancreatic abnormality (preferably both). We suggest that the sweat test should be repeated and the diagnosis reviewed in all patients with cystic fibrosis about one year after the initial diagnosis. Evaluation of problems in diagnosis is an important function of a cystic fibrosis referral centre.

We thank the department of chemical pathology for the excellent sweat tests.

\section{References}

1 Smalley CA. Addy DP. Anderson CM. Does that child really have cystic fibrosis? Lancet 1978;ii:415-7.

2 David TJ, Phillips BM. Overdiagnosis of cystic fibrosis. Lancet 1982:ii:1204-5.

${ }^{3}$ Littlewood JM, Losowsky MS. Modern investigation of gastrointestinal disease. In: Meadow $\mathrm{R}$, ed. Recent advances in paediatrics. London: Churchill Livingstone, 1984:77-101.

${ }^{4}$ Congdon PJ, Bruce G, Rothburn MM, et al. Vitamin status in treated patients with cystic fibrosis. Arch Dis Child 1981;56: 708-14.

5 Corey M, Guskin K, Durie P, Levison H, Forstner G. Improved prognosis in cystic fibrosis patients with normal fat absorption. J Pediatr Gastroenterol Nutr 1984;3(suppl 1):99-105.

${ }^{6}$ Green A, Dodds P, Pennock C. A study of sweat sodium and chloride; criteria for the diagnosis of cystic fibrosis. Ann Clin Biochem 1985;22:171-6.

Correspondence to Dr JM Littlewood, Department of Paediatrics and Child Health, St James's University Hospital, Leeds LS9 7TF.

Received 29 May 1987

\title{
Cerebral arteriovenous malformation in a neonate: treatment by embolisation
}

\author{
F B McCORD,${ }^{*}$ M D SHIELDS, ${ }^{*}$ A McNEIL,$\dagger \mathrm{H}$ L HALlidAY, ${ }^{*}$ G McCluRE, ${ }^{*}$ \\ AND M McC REID*
}

*Department of Child Health, The Queen's University of Belfast, Royal Maternity Hospital, and †Department of Radiology, Royal Victoria Hospital, Belfast

SUMMARY A neonate with an aneurysm of the vein of Galen was treated by embolisation using Gianturco coils. Doppler ultrasound examination showed that blood flow in the internal carotid artery decreased while that in the pericallosal artery increased after occlusion, suggesting a 'steal phenomenon' with blood directed preferentially towards the aneurysm. 
Aneurysm of the vein of Galen presenting with congestive heart failure during the neonatal period is rare but carries a high mortality. ${ }^{12}$ Stanbridge et al reported that the diagnosis could be made noninvasively by two dimensional echocardiography and cerebral ultrasound. ${ }^{2}$ Surgical intervention ${ }^{3}$ or embolisation under neuro-radiological guidance has been used in older children and adults but outcome in the neonate has been almost universally disappointing. Mickle and Quisling reported a new non-surgical technique of transtorcular embolisation, but had a disappointing result in neonates. ${ }^{4}$

We report the case of a neonate with an aneurysm that was successfully occluded using Gianturco coils. ${ }^{5}$ Cerebral blood flow, cardiac output, and flow within the aneurysm were measured before and after treatment using pulsed Doppler ultrasonography.

\section{Case report}

A baby girl born at term weighing $2800 \mathrm{~g}$ developed congestive heart failure on the third day. Clinically she had an active praecordium, prominent pulsation of the neck vessels and a faint bruit over the anterior fontanelle. Two dimensional echocardiography showed a structurally normal heart with dilatation of the ascending aorta and of the superior vena cava. Cerebral ultrasound examination showed an aneurysm of the vein of Galen that was seen as a large echo free space, $2 \mathrm{~cm} \times 2 \mathrm{~cm}$, lying centrally and posterior to the third ventricle. Turbulent blood flow within the defect was detected by pulsed
Doppler ultrasonography. Aortic arch angiography and computed tomography scanning with contrast confirmed the diagnosis (figure). Her congestive heart failure was partially controlled by digoxin and diuretics. Subsequently embolisation with Gianturco occluding emboli ${ }^{5}$ was carried out by retrograde insertion of the coils through an occipital burr hole, along the straight sinus, and into the aneurysm. These helical stainless steel coils are $5 \mathrm{~cm}$ long with thrombogenic Dacron wool filaments embedded along a $4 \mathrm{~cm}$ length from the distal tip and are designed for arterial occlusion. This procedure took place in two steps: initially 15 coils were placed in the aneurysm at the age of 18 days, and three weeks later a further nine coils were inserted to occlude the aneurysm completely.

Postoperatively her clinical recovery was rapid, the cranial bruit disappeared, and medical treatment for the heart failure was stopped. After embolisation pulsed Doppler ultrasound examination showed the absence of flow within the aneurysm suggesting occlusion of the defect. At the age of 21 months she seemed to be developing normally, her head circumference growing along the 50th centile. Repeat ultrasound scans showed no cerebral ventricular dilatation.

Cerebral blood flow was estimated by Doppler ultrasound before and after embolisation (table) using peak systolic velocity and area under the curve in the pericallosal and internal carotid arteries. Cardiac output from the ascending aorta was also measured using pulsed Doppler ultrasonography before and after treatment.
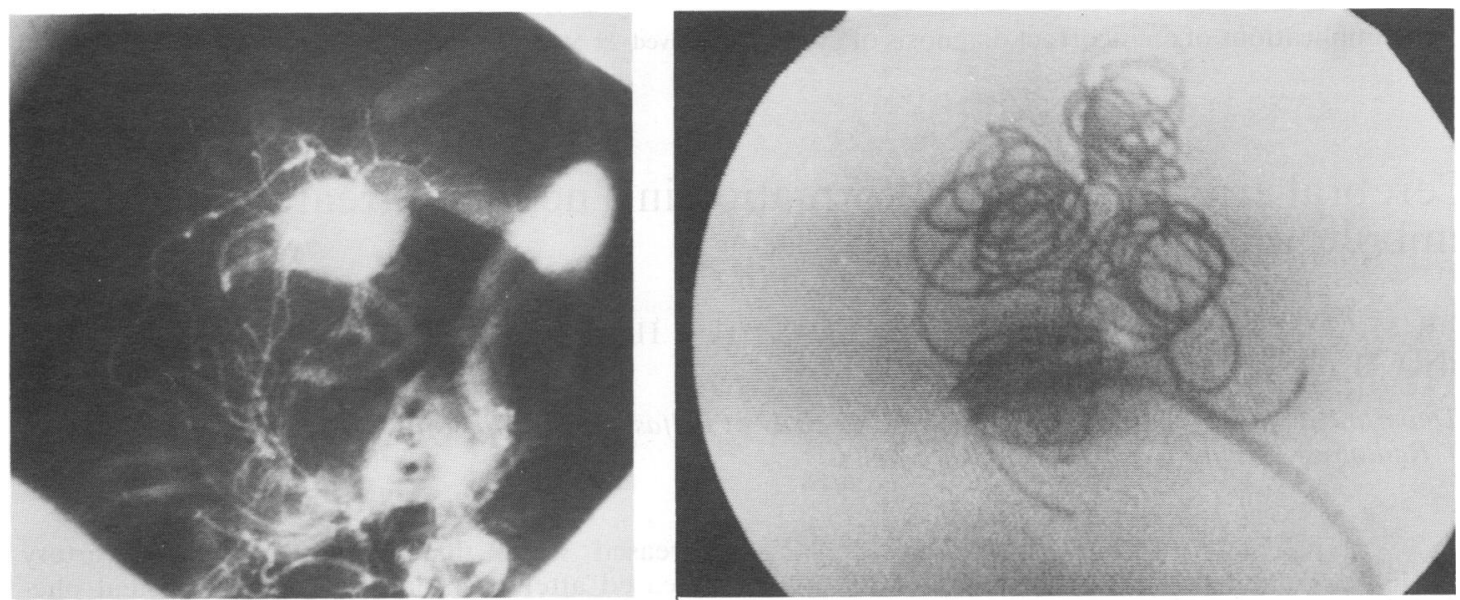

Figure Left: angiographic contrast image of aneurysm of vein of Galen (centre); drainage is posteriorly towards the torcula (right). Right: intraoperative fluoroscopic image (enlarged) showing introducer in situ and position of the Gianturco coils within aneurysm. 
Table Doppler ultrasound measurements of cerebral blood flow before and after occlusion of the arteriovenous aneurysm

\begin{tabular}{llll}
\hline Measurement & $\begin{array}{l}\text { Before } \\
\text { occlusion }\end{array}$ & $\begin{array}{l}\text { After } \\
\text { occlusion }\end{array}$ & $\%$ Change \\
\hline $\begin{array}{l}\text { Peak systolic velocity } \\
\text { (cm/second): }\end{array}$ & & & \\
$\quad \begin{array}{l}\text { Internal carotid artery } \\
\quad 109\end{array}$ & 16 & 36 & -49 \\
$\begin{array}{c}\text { Area under the curve } \\
\quad \text { (planimeter units/minute): } \\
\quad \text { Internal carotid artery }\end{array}$ & 282 & 191 & -32 \\
$\quad \begin{array}{l}\text { Pericallosal artery } \\
\text { Cardiac output } \\
\text { (ml/kg/minute) }\end{array}$ & 136 & 341 & +151 \\
\hline
\end{tabular}

After treatment there was a substantial reduction in flow through the internal carotid arteries feeding the arteriovenous malformation and increased flow in the pericallosal arteries. After embolisation the cardiac output fell by $41 \%$ from $495 \mathrm{ml} / \mathrm{kg} /$ minute to $291 \mathrm{ml} / \mathrm{kg} /$ minute.

\section{Discussion}

Aneurysm of the vein of Galen is a rare cause of congestive cardiac failure in the neonatal period. Auscultation of a cranial bruit can hasten diagnosis, but this finding is not invariably present. Jeideikin et al, in a review of 12 cases, noted that a cranial bruit was present at initial diagnosis in only two $(17 \%)$ but at some time during life was heard in $75 \%$. ${ }^{6}$

To our knowledge this is the first report of successful retrograde embolisation of an aneurysm of the vein of Galen in a neonate using Gianturco coils. Previous reports have indicated a uniformly poor outcome of affected neonates, whether treated or not, with a high incidence of neurological handicap in the few survivors. In this case nonsurgical treatment resulted in a good outcome, growth and development being normal at the age of 21 months.

Our Doppler haemodynamic findings suggest the presence of a 'steal phenomenon', with blood directed preferentially towards the malformation with a low vascular resistance and away from other areas of the brain. This steal phenomenon may be the cause of the ischaemic brain lesions found at necropsy by, Norman and Becker in their series of seven neonates with aneurysms of the vein of Galen (cerebral infarction $\mathrm{n}=2$; periventricular leucomalacia $n=5$; and haemorrhagic infarction $n=2){ }^{1}$

We acknowledge the expert technical assistance and advice of $\mathrm{Dr}$ HC Mulholland, Royal Belfast Hospital for Sick Children, and Mr D Gordon, Royal Victoria Hospital. We also thank Miss M Weller for typing the manuscript.

\section{References}

${ }^{1}$ Norman MG, Becker LE. Cerebral damage in neonates resulting from arterio-venous malformation of the vein of Galen. J Neurol Neurosurg Psychiatry 1974;37:252-8.

2 Stanbridge R de L, Westaby S, Smallhorn J, Taylor JFN. Intracranial arterio-venous malformation with aneurysm of the vein of Galen as cause of heart failure in infancy. Echocardiographic diagnosis and results of treatment. $\mathrm{Br}$ Heart $J$ 1983;49:157-62.

3 Amacher AL, Shillito J. The syndromes and surgical treatment of aneurysms of the great vein of Galen. J Neurosurg 1973;39:89-9r.

${ }^{4}$ Mickle JP, Quisling RG. The transtorcular embolization of vein of Galen aneurysms. J Neurosurg 1986;64:731-5.

5 Chuang VP, Wallace S, Gianturco C. A new improved coil for tapered-tip catheter for arterial occlusion. Radiology 1980;135:507-9.

6 Jedeikin R, Rowe RD, Freedom RM, Olley PM, Gillan JE. Cerebral arteriovenous malformation in neonates - the role of myocardial ischaemia. Pediatr Cardiol 1983;4:29-35.

Correspondence to Dr MD Shields, Royal Maternity Hospital, Belfast BT12 6BB.

Received 9 June 1987 